\title{
Rapid Response in an Uncertain Environment: Study of COVID-19 Scientific Research Under the Parallel Model
}

\author{
Xi Cheng $\mathbb{D}^{\prime}$, Qiyuan Chen $\mathbb{D}^{\prime}$, Li Tang $\mathbb{D}^{2}$, Yue Wu $\mathbb{D}^{\prime}$, Haoran Wang $\mathbb{D}^{\prime}$, Guoyan Wang $\mathbb{D}^{\prime}$ \\ 'Department of Digital Communication, Soochow University, Soochow, Jiangsu, 215I23, People's Republic of China; ${ }^{2}$ Department of Public \\ Administration, Fudan University, Shanghai, 200433, People's Republic of China
}

Correspondence: Guoyan Wang, Department of Digital Communication, Soochow University, Soochow, Jiangsu, 2I5I23, People's Republic of China, Tel +86-19951313650, Email gywang@suda.edu.cn

\begin{abstract}
Purpose: The rapid response of COVID-19 scientific research played a significant role in pandemic prevention and control but failed to block the spread of the pandemic rapidly. Besides the complexity of the virus, the effectiveness of control and prevention measures, and other factors, the adaptation of the mode of conducting scientific research is also crucial for the prevention and control of COVID19. In this study, a parallel model was used to explore the effects of the rapid scientific response on COVID-19 to assess why pandemics continue to spread under rapid response.

Analysis: This study presents the response of scientific research based on country/region and publication dimensions after analyzing COVID-19 studies in the Web of Science and PubMed databases. Co-occurrence analysis of items was used to determine the generation rate of COVID-19 research under different topics to identify the reflected innovation model.

Results: More manifestations on rapid response of COVID-19 research, especially compared with the linear model of SARS research, showed that the COVID-19 research followed a parallel or concurrent innovation model.

Conclusion: Early multi-stakeholder partnership, convenient information sharing, and improved research competence promote the parallel model in COVID-19. Meanwhile, the uncertainty of the COVID-19 virus and the adverse effect of rapid response may limit the time efficiency of the parallel model. In conclusion, the rapid prevention and control of the pandemic cannot fully rely on scientific research but requires more combined effort under an uncertain global setting.
\end{abstract}

Keywords: parallel model, rapid response, COVID-19, scientific research

\section{Introduction}

\section{Background}

The rapid response of scientific research is vital during public health emergencies. For instance, experts from different domains developed various intervention strategies ranging from genetically modified mosquitoes to chemical sprays based on environmental assessments when the Zika virus (ZIKV) threatened the Americans in 2016. Moreover, appropriate animal models were developed, enhancing the pathological understanding of ZIKV, antiviral testing, and vaccine evaluation. ${ }^{1}$ However, clinical data collection was suspended during the outbreak of the 2009 influenza A virus subtype H1N1 (A/H1N1), limiting the development of practical guidelines for the management of critically ill patients. As a result, a $40 \%$ death rate occurred in children and was misjudged at the early stage. ${ }^{2}$

Furthermore, scientific research rapidly responded during the COVID-19 outbreak (See Supplemental Table 1 and Figure S1). For instance, the number of publications related to COVID-19 doubled every 20 days on average (see: www. sciencemag.org/news/2020/05/scientists-are-drowning-covid-19-papers-can-new-tools-keep-them-afloat) during the early stage. Meanwhile, vaccine research and development (R\&D) time has been reduced from 10-15 years to 1-2 years. ${ }^{3}$ Previous studies explored the reason for this unprecedented surge of COVID-19 publications based on various 
perspectives, such as the improved quality of academic research, ${ }^{4}$ research experience, ${ }^{5}$ the severity of the COVID-19 pandemic, ${ }^{6}$ changes to the peer-review system, ${ }^{7}$ and various paper-sharing platforms. ${ }^{8}$

An innovation model is a form of innovation ${ }^{9}$ that affects the speed of scientific research. The parallel/concurrent innovation model is different from the linear model, ${ }^{10,11}$ and has an outstanding advantage on time-saving since different innovation phases are executed in parallel rather than in sequence. ${ }^{10,12-14}$ As a result, the parallel model has been widely used in many innovation fields. ${ }^{12,13}$ Under the parallel model, the time required for research to reach the publication stage is shortened, thus promoting a quick response. China, Europe, and the USA tried to assess the time priorities associated with COVID-19 vaccines or drugs (see: https://www.nytimes.com/2020/03/19/us/politics/coronavirus-vaccine-competi tion.html; https://www.washingtonpost.com/health/2020/06/03/coronavirus-vaccine-global-race/), which became essential for reshaping national image and status.

Although there was rapid response on COVID-19 scientific research, the duration of COVID-19 has been longer than that of SARS and MERS, which are also caused by Human coronaviruses (hCoV). Multiple factors, such as virus complexity and effectiveness of management measures, jointly determine the duration of pandemic prevention and control. ${ }^{15}$ The complexity of technology also determines the implementation effect of the parallel model. For instance, the parallel model can bring more significant temporal advantages in the technology with a low degree of determinism. ${ }^{16-19}$ Meanwhile, the negative effects caused by the rapid research output under the parallel model, such as academic paper retractions, ${ }^{20}$ the emergence of infodemic, ${ }^{21}$ side effects of drugs and vaccines,${ }^{22,23}$ may "weaken" the benefits of timeconsuming.

This study explored why the quick response did not stop the pandemic spread based on the adaptation of the parallel model of conducting scientific research. The research first demonstrated that the parallel model was reflected in scientific studies during the COVID-19. Grouping of items from COVID-19 papers analyzed via VOSViewer (1.6.15) software revealed that the various COVID-19 research topics started to appear in the 2nd month after the first case of COVID-19 was reported. However, it took about seven months for the publications of SARS, which is also in lineage $\beta$ in $\mathrm{hCoV}^{26}$ to sequentially refer to all the eight themes. Therefore, the scientific research on different themes of COVID-19 followed a parallel model, while SARS research followed a linear model. Unlike most previous studies exploring the application of the parallel model based on product innovation, this research introduced the innovation model in the management of emergencies to further explain the parallel model. ${ }^{12,13,24,25}$ Moreover, this study explored the existence of a parallel model through the knowledge graph analysis of published papers, thus innovating and enriching the measurement index of the parallel model.

\section{Literature Review}

The innovation process has several stages, including scientific research. ${ }^{9,27}$ The innovation process can follow a flexible process, indicating that the different stages can operate without following a temporal sequence. ${ }^{13}$ Rothwell ${ }^{28}$ classified five generations of innovation models based on their history. The first and second-generation models were linear models, where different innovation phases are executed one after another following a time sequence. ${ }^{28}$ The parallel model is the opposite of the linear model, where different innovation phases are simultaneously executed over a period of time e $^{13,14}$ and are regarded as the main feature of the integrated model of the fourth generation innovation model. ${ }^{28,29}$ The fourthgeneration innovation model was proposed in the 1980s and 1990s, mainly based on the emergence of a new generation of manufacturing equipment based on IT technologies shortening the product manufacturing cycle. Moreover, studies have shown that the innovation processes in firms are parallelized. ${ }^{30}$ Successful corporate innovation strategies are driven via centralized integration and parallel development processes. ${ }^{31}$ Therefore, parallel or concurrent model constitutes the fifth- ${ }^{28}$ and the sixth-generation innovation models. ${ }^{32}$ Moreover, the scientific research phase can be parallel with other innovation phases ${ }^{12,33}$ or within itself. ${ }^{25}$

Other scholars refer to the parallel development of the product production process as concurrent engineering (CE). ${ }^{34-37}$ Parallel workflow is the first essential element in CE, indicating that various stages of product production run in the partial or full parallel state. ${ }^{18,36}$ Furthermore, parallel engineering emphasizes the need for all departments to work together from the beginning and consider the problems encountered from the product design to production, also known as "integrated 
problem solving" ${ }^{38}$ Besides parallel workflows, early involvement of Departments and teamwork are critical in parallel engineering. ${ }^{35}$

The parallel model is time-saving ${ }^{13,25,38-41}$ and less costly. ${ }^{11,35,42-44}$ However, some scholars believe that a parallel model can significantly increase costs than the linear models ${ }^{45,46}$ unless the enterprise chooses the time-priority factor. ${ }^{47}$ For instance, the parallel model may suit emerging technologies and start-ups that value time to market. ${ }^{12}$ Multi-party seeks to contain the spread of pandemic without delay in the fight of COVID-19, consistent with the target of parallel model.

\section{Methods}

In this study, the rapid response of COVID-19 research is presented based on three dimensions: First, the research records the publications of each country within one year after the first case of COVID-19 to show the rapid response of different countries. According to $\mathrm{Wu}$ and McGoogan (December 8, 2019), ${ }^{48}$ the date of the first disclosed case was set as the start time of research. The year was divided into 12 intervals, with the first interval being between December 8, 2019, and January 7, 2020. Data were retrieved from the Web of Science, and only the Article and Review literature were used. The search was conducted on October 1, 2021, and a supplemental search was conducted on November 4. Meanwhile, the research established the emergence time of local cases in different countries using Wikipedia.

Second, COVID-19-related publications and journals published at different intervals were selected as the second dimension (obtained from the PubMed database). Furthermore, the number of publications and journals one year after the first case of SARS was reported was used as the standard to show the contrast between COVID-19 and other HCoV epidemics based on scientific research response speed. The first case of SARS was reported on November 16, 2002, according to $\mathrm{Wu}$ and McGoogan. ${ }^{48}$ Of the 12 intervals, the first interval spans from November 16, 2002 to December 15, 2002. The publication-journal ratio was used for comparison since the number of journals in the time range of research

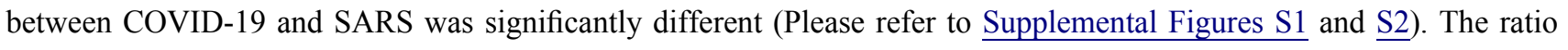
was obtained by dividing the number of COVID-19/SARS articles by the number of journals during each respective interval.

Unlike the two previous dimensions, the response speed of different main topics of COVID-19 research was used as the third and a micro perspective to judge the fast response. Eight issues of COVID-19 research published by Johns Hopkins University (see: ncrc.jhsph.edu/topics, Diagnostics, Modeling, Epidemiology, Pharmaceutical Interventions, Non- Pharmaceutical Interventions, Clinical Presentation \& Prognostic Risk Factors, Vaccines, Ecology \& Spillover) were used as classification basis of themes to identify the speed of scientific research conducted on different topics (Table 1). The speed of occurrence of different research themes was explored via a co-occurrence analysis to

Table I First Occurrence Time of Items for Different Research Themes of COVID-I9 and SARS

\begin{tabular}{|l|c|c|}
\hline \multirow{2}{*}{ Category } & SARS & Conth from the First Global Case (Interval) \\
\cline { 2 - 3 } & 4 & 2 \\
\hline Clinical Presentation \&Prognostic Risk Factors & 5 & 2 \\
\hline Ecology & 5 & 2 \\
\hline Non-Pharmaceutical Interventions & 5 & 2 \\
\hline Diagnostics & 6 & 2 \\
\hline Modeling & 6 & 2 \\
\hline Pharmaceutical Interventions & 6 & 2 \\
\hline Epidemiology & 7 & 2 \\
\hline Vaccine & 6 & 2 \\
\hline
\end{tabular}




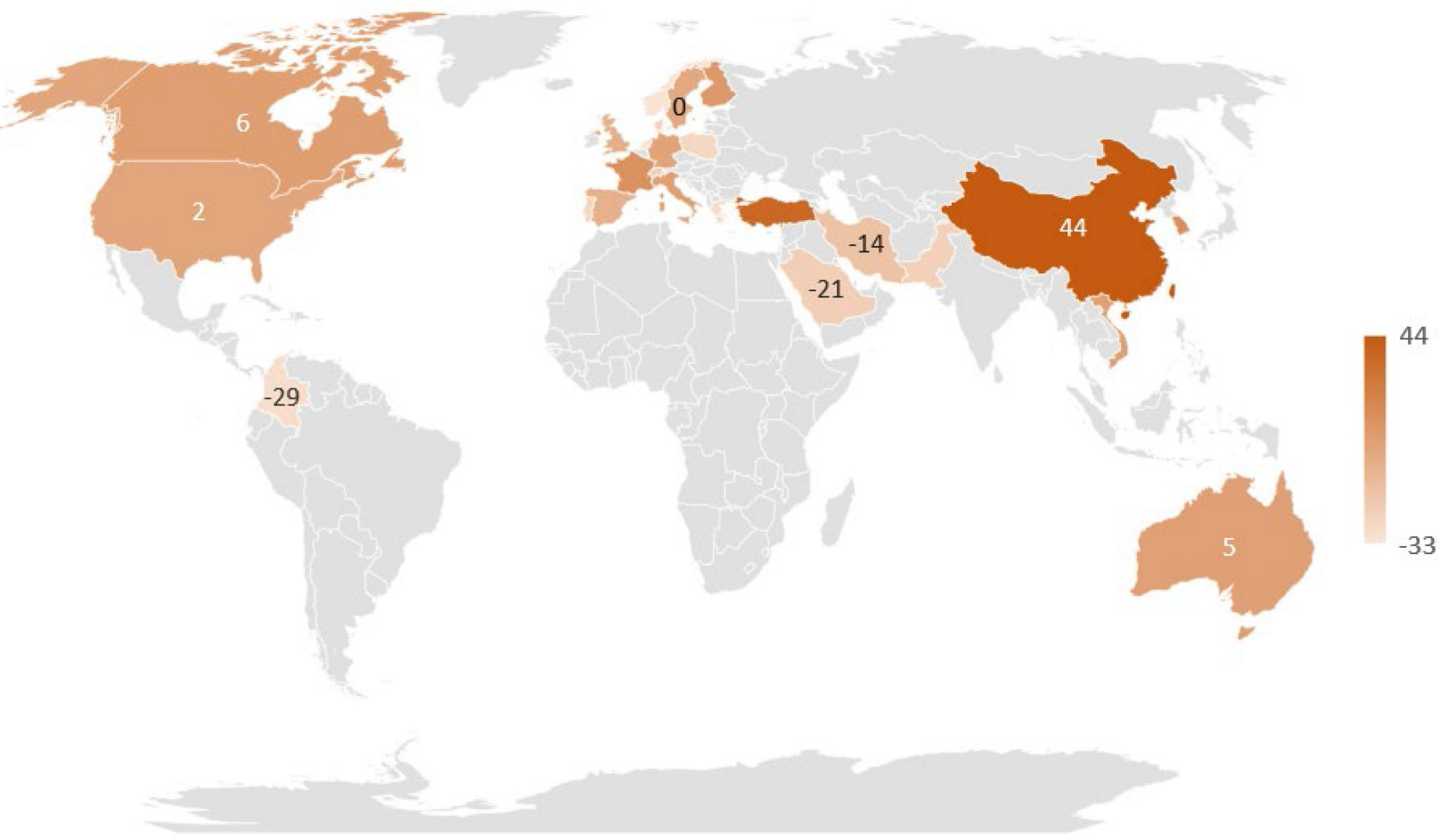

Supported by Microsoft Bing (e) DSAT Editor, DSAT for MSFT, GeoNames, Microsoft, Navinfo, TomTom, Wikipedia

Figure I Comparison of the number of days for a response in rapid response countries.

scientifically and accurately compare the speed of the main research field. Co-occurring items were used as a reference to establish the research focus and connection of bulk publications. ${ }^{49,50}$ Co-occurrence analysis of items from VosViewer (1.6.15) software was used to determine the research themes. The terms were categorized based on meanings and mentions in the text to find the period of the first occurrence of the terms in different categories. Similarly, the research recorded the emergence interval of different research topics of SARS to compare the response rate of different research topics between COVID-19 and SARS (The COVID-19 research classification standard was adopted due to the lack of an authoritative classification of SARS research. Besides, they are both caused by coronaviruses and have similar phylogeny and virus receptors). ${ }^{51}$

\section{Results}

\section{Rapid Response from a National Perspective}

Twenty-eight countries/regions published papers during the second month after the first global case of COVID-19. In contrast, only one country published SARS-related papers after the fourth month of SARS emergence (see Supplemental Tables 1 and 2). Furthermore, the intervals between the publication of the first paper and the first local case varied among various countries/regions (independent of the country the first author belongs to). The stronger colors in Figure 1 indicate longer publication intervals after the first native case. It took an average of 4.1 days from the first native case for these 28 quick-response countries to publish their first paper (Supplemental Table 2). The number of COVID-19 publications per month in the representative countries rapidly increased, especially for North America, Europe, Oceania, and East Asia (economically developed regions). More details are shown in Supplemental Table 3 and Figure S3. 


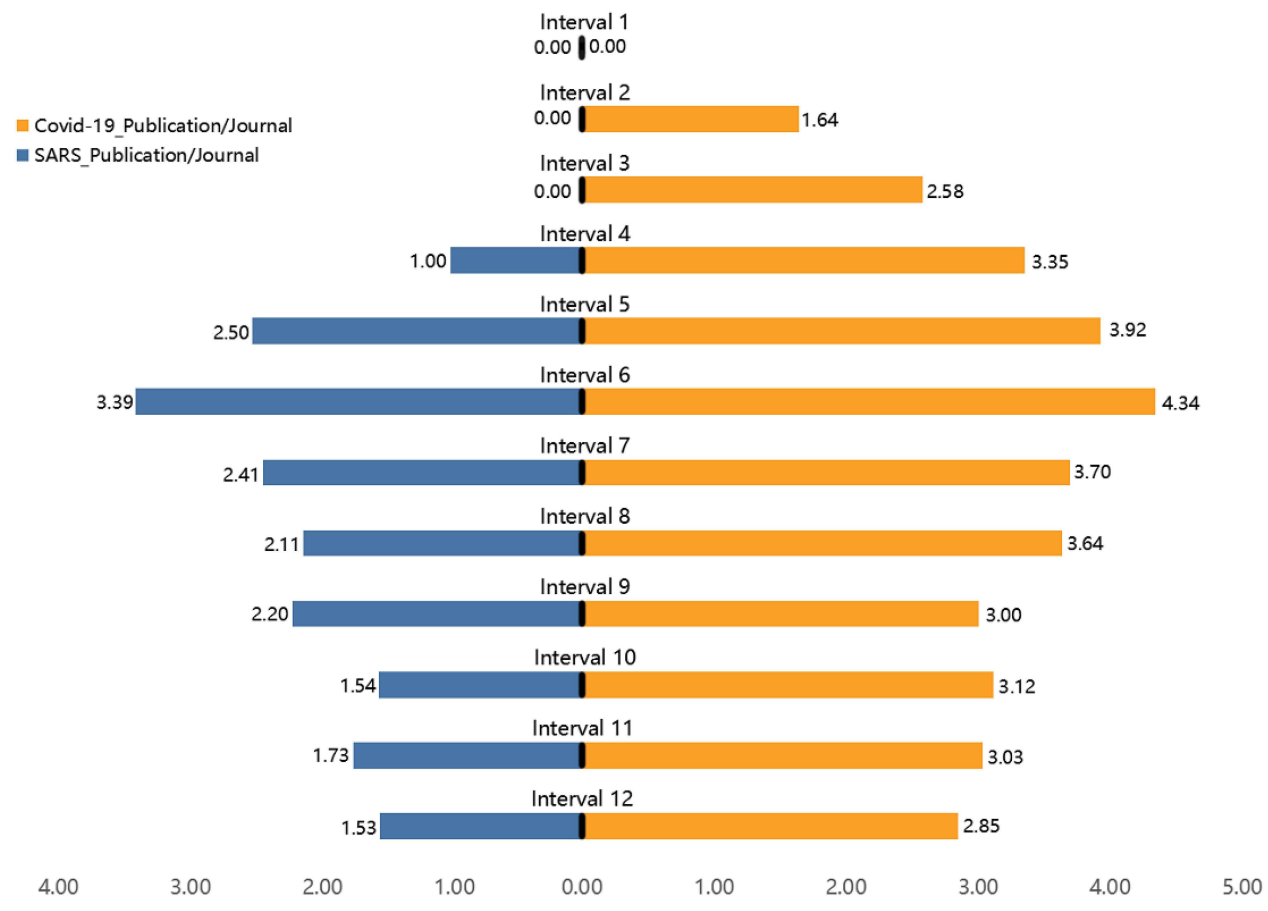

Figure 2 The publication-journal ratio of COVID-19 and SARS one year after the first disclosed case.

\section{Rapid Response from a Publication Perspective}

The number of COVID-19-related publications rapidly increased in the early period. The publication-journal ratio in the research time range was 1.94 times higher than that in one year after SARS emergence (Figure 2 and Supplemental Table 4). Notably, the number of journals increased with increasing number of papers. The Journal Citation Reports (JCR) database showed that the journals belonging to the following five categories had the most COVID-19 and SARS papers: Virology, Infectious Diseases, Public, Environmental \& Occupational Health, Medicine, General \& Internal, Immunology. The number of journals in the five categories increased by more than 2.72-folds from 2003 to 2020, especially, journals in Public, Environmental \& Occupational Health category increased by 4.24-folds (see Supplemental Table 5). This result indicated the increase of review efficiency due to the review reform and the advanced carrying capacity of each journal due to diversified publishing channels.

\section{Rapid Response from a Research Theme Perspective}

The items under each of the eight research categories appeared in the second intervals after the emergence of the first global COVID-19 case. In contrast, the items under the eight research categories appeared from the fourth to the seventh months after the first SARS case (see Supplemental Table 6 for details of co-occurrence items from different categories during the month of their first appearance). The response speed of the main topics of COVID-19 and SARS-related studies indicated the parallel and linear models, respectively (Table 1). Also, the parallel development of different themes indicates that the rapid response of COVID-19 scientific research penetrated various themes. The fully accelerated COVID-19 scientific research also leads to rapid response. Notably, the different topics of general medical research were in sequential order and were closely related to each other. For instance, vaccine research must be conducted based on information, such as viral protein sequences and structures. ${ }^{51}$ It belongs to the category of epidemiology based on the Johns Hopkins University classification. SARS follows the traditional medical sequence, which indicates that the "epidemiology" appeared before "vaccine". The overall speed-up in COVID-19 avoids uneven progress in conducting different research themes. Moreover, successful resistance to epidemics requires the concerted collaboration of scientific research on all themes. The parallel model prompts the production of several scientific publications within a short period, implying a quick response. 


\section{Discussion}

\section{Reasons for the Appearance of the Parallel Model in COVID-19 Research}

The parallel model promotes a rapid response in the available scientific research. However, the application of this model also requires certain conditions. ${ }^{24}$ In this study, COVID-19 scientific research met the following three elements essential to the parallel model based on various studies, including Salomone, ${ }^{52}$ Koufteros et al, ${ }^{35}$ Valle and Vazquez-Bustelo, ${ }^{18}$ and Karningsih et al. ${ }^{53}$

First, early multi-party partnership and cooperation are essential in the parallel model. ${ }^{18,35,52,53}$ The parallel model focuses on the coordinated operation of various divisions in different stages, thus emphasizing collaboration among all parties, and can create multi-perspective feedback to reduce rework. ${ }^{18}$ Moreover, the parallel development of different stages demands overall planning of the overall operation development in the early stage ${ }^{43}$ to maximize CE. The involvement of many parties, including biology or medicine, the model forecast in the information field, guidance on the rehabilitation of patients or professionals in the psychology field, and exploring the mechanisms of infodemic transmission in the Communication field is crucial for the prevention and control of COVID-19. Close cooperation among various disciplines is one of indications that the COVID-19 pandemic has changed the culture of scientific research. Scientific collaboration among different backgrounds and countries has reached unprecedented levels. ${ }^{55,56}$ Therefore, the early stage of the COVID-19 fits the parallel model that requires early multi-party involvement and collaboration.

Second, parallel models depend on information sharing. ${ }^{18,35,53}$ Information sharing influences the efficiency of parallel model execution. ${ }^{13}$ The development of the modern internet and Digital technologies has significantly facilitated the exchange and storage of information, which is suitable for parallel models. ${ }^{28,29}$ Technology has introduced a more expansive range of options and higher efficiency for information sharing even when the participants are at home. The diversity of journals and publication platforms promotes rapid information sharing. ${ }^{56}$ Moreover, preprints have helped more researchers access high-priority clinical data in the life sciences. ${ }^{57}$ Furthermore, online offices or meeting software have saved the traveling time to offices or conference places, thus enhancing information sharing from professionals or scientists to the public. For instance, the number of scientists engaged in "Skype a Scientist" from late February to July, 2020, doubled since its creation in 2017 (See: https://www.nature.com/articles/d41586-020-02075-0).

Third, an inevitable development basis, including advancing previous experience and research strength, ${ }^{24,53}$ is essential for parallel model implementation. Preliminary studies on other infectious diseases, such as SARS, MERS, and H1N1, provided a basis for a quick response of COVID-19 research on different topics. McDermott and Handfield ${ }^{24}$ indicated that the parallel model is not applicable for breakthrough innovations. This is because the environment such innovation relied on has significantly changed throughout the innovation, ${ }^{58}$ affecting the communication of available information, on which parallel development is dependent. ${ }^{24}$ Furthermore, breakthrough innovations address fundamental changes in core technologies. ${ }^{59}$ It is challenging to conduct downstream-biased work without the needed experience and foundation. In summary, the parallel model is unsuitable for innovation areas with high technological uncertainty. ${ }^{16,24}$ Little was known about human infections caused by coronaviruses ${ }^{60}$ until the successful fight against SARS, which provided a valuable experience in virology and pathology of the COVID-19 infection. ${ }^{61}$ For instance, researchers designed vaccine candidates several weeks after the emergence of the SARS-CoV-2 virus, mainly due to the experience obtained from the preclinical and clinical data from previous SARS-CoV and MERS-CoV vaccine trials. ${ }^{62}$ For COVID-19 early treatment, drugs, such as remdesivir for SARS and MERS, were used. ${ }^{63}$

The advances in research technologies and platforms reflect the improvement of research strength (quality and quantity). The generalization of scientific models is one of the representative cases. Scientific models are crucial for predicting and responding to complex biological, social, and environmental crises, including epidemics. ${ }^{64} \mathrm{~A}$ decade ago, mathematical models could only be used by privileged epidemiologists and were not available to the public. ${ }^{65}$ However, many academic papers using mathematical models and simulators to assess the progress of COVID-19 locally or globally have been published since the models are currently easily accessible. Models can enhance the initial screening of numerous drugs and the early recognition of viral transmission capacity ${ }^{66,67}$ Research platforms are also essential in research. For instance, advances in scientific research platforms have enhanced vaccine development, providing adequate 
conditions for rapid vaccine development. ${ }^{5}$ Viral- and protein-based vaccine platforms are widely used due to their early established platform in developing appropriate vaccines. Therefore, fully inactivated viral and recombinant protein vaccines can quickly reach clinical trials. ${ }^{68}$

\section{Implications of Parallel Models}

Although a parallel innovation model may bring the quick response of COVID-19 scientific research, it cannot rapidly prevent the pandemic. This can be explained from two perspectives based on the parallel model: the efficiency of the parallel model applied to technologies with different uncertainty degrees and the negative implications of rapid research output.

It is unclear whether parallel models are suitable for techniques with high uncertainty. ${ }^{18,36}$ COVID-19 epidemic has an aspect of uncertainty. For instance, Zhou et al ${ }^{69}$ indicated that $2019-\mathrm{nCoV}$, which triggers COVID-19, has $79.5 \%$ similarity to the genome of SARS-CoV, which triggers SARS. However, Lu et al ${ }^{70}$ showed that the genome sequences of 2019-nCoV, SARS-CoV, and MERS-CoV are significantly different. Petrosillo et al ${ }^{71}$ indicated that it is unclear whether 2019-nCoV and SARS-Cov are related. Therefore, COVID-19 research provides insights into scientific research execution and epidemic prevention policy development based on similarities with pre-existing diseases. For instance, studies found that bats are the natural hosts of SARS-like coronaviruses more than two years after the SARS outbreak. ${ }^{72}$ However, Zhou et al ${ }^{69}$ suggested that $2019-\mathrm{nCoV}$ may have originated from a bat one month after the pandemic outbreak after comparing the 2019-nCoV and SARS-CoV gene sequences. Therefore, the significantly shortened R\&D time for the COVID-19 vaccine could be due to the great experience gained from the preclinical and clinical data from previous H1N1, SARS-CoV, and MERS-CoV vaccine trials. ${ }^{62}$ Nevertheless, the uncertainty of COVID-19, such as the inability to detect asymptomatic patients at an early stage, ${ }^{73}$ the emergence of variants, ${ }^{74}$ and the fact that the 14-day incubation period is no longer fully applicable in later clinical observation, ${ }^{75}$ significantly limit the role of scientific research on pandemic prevention and control of COVID-19, compared to SARS and MERS. Thus, the outbreak may last longer. The comparison of the research progress at different certainty degrees of COVID-19 has shown that the time-saving factor of the parallel model has a significant effect on the high certainty side than on the low certainty side. The effect of parallel model practice on uncertain technology is unclear since it considers all new product development activities, ${ }^{43}$ making it difficult to predict all activities of higher uncertainty technologies. The time reduced when implementing a parallel model is more uncontrollable in a high uncertainty environment than within more deterministic technologies, possibly leading to rework and other less favorable situations undermining innovation efficiency. ${ }^{16,19,76}$ Furthermore, the cooperation point between departments in the parallel model may be harder to find in a high uncertainty environment. Hoedemaker et al ${ }^{77}$ also indicated that the higher the complexity of the project, the higher the limitations of the parallel model. Valle and Vazquez-Bustelo ${ }^{18}$ showed that the parallel model affects radical and incremental innovation differently. It can reduce time in incremental innovation while reducing cost in radical innovation. Therefore, parallel models may not have a significant time advantage in technologies with high uncertainty. However, it is unknown whether parallel models can increase or decrease cost in high uncertainty technologies since there is no valuable cost reference for COVID-19.

Furthermore, the accelerated speed of scientific output has some limitations. The increased scientific research papers in the COVID-19 epidemic have increased literature creation and review workflow cycle (See: https://www.nytimes.com/ 2020/04/01/world/europe/coronavirus-science-research-cooperation.html). Palayew et al ${ }^{78}$ noted that the median time required by the authors of COVID-19 papers from submission to journal acceptance is six days, significantly shorter than the 100 days representing the average period for most journals to reach a final decision. In addition, the quality behind the several emerging papers may be undermined due to article explosion. ${ }^{7}$ Higher degrees of parallel development may diminish the quality of the final product. ${ }^{10}$ Moreover, the probability of occasional error in a review may increase due to huge demand for article review. Sørensen and Mattsson ${ }^{13}$ indicated that time-saving results in insufficient information about upstream activities, affecting downstream activities that rely on such information. As a result, the degree of time reduction may result in errors during peer review. ${ }^{56}$ The publication of several questionable papers may provide false references for subsequent studies (See: https://www.science.org/content/article/many-scientists-citing-two-scandalous$\underline{\text { covid-19-papers-ignore-their-retractions) and guide evidence-based decision-making in inappropriate evidence, }{ }^{79} \text { leading }}$ 
to infodemic. Academic publications in preprint platforms without validation and review are widely disseminated, leading to infodemic instead of social networks. ${ }^{21}$ For instance, a study showed that snakes are the hosts of COVID-19. ${ }^{80}$

Rapid research also shortens the test period of vaccines and drugs. COVID-19 has changed the duration of medicine and vaccine development from $R \& D$ to validation. Unlike emerging technologies, the pharmaceutical industry is more tolerant to time costs to ensure safety. It takes about 12 years or more to develop a new drug from target identification to market approval. ${ }^{81}$ Vaccines also require ten years to become available to the public. ${ }^{3}$ Nevertheless, a long period limits the wish to overcome diseases, especially highly infectious diseases spreading fast. Therefore, the selection and implementation of COVID-19 treatment and protection measures may not follow the random timeline. Many compassionate drugs (remdesivir) have emerged, ${ }^{82}$ reducing the time between drug screening and clinical application. ${ }^{83}$ The Chinese herbal formula has also been established. Vaccine development will also be cut from first volunteer vaccination to first approval in less than one year (See: https:/www.biopharmadive.com/news/coronavirus-vaccine-pipeline-types/ 579122/). However, the limitations of fast introduction of relevant drugs and vaccines are emerging. First, the generalizability and side effects of the drugs and vaccines should be assessed. The development of COVID-19 drugs and vaccines requires access to information on viral protein sequences and structures. ${ }^{51}$ The data presented in the previous section show that vaccine and drug-related studies have been conducted since the second interval after the first disclosed case. As a result, the effectiveness of drugs and vaccines has been questioned in the late emergence of variants, ${ }^{84}$ such as breakthrough infections. Therefore, the call for improving the broad spectrum of drugs and vaccines is gradually increasing. ${ }^{85}$ Second, the side effects of the clinical use of some drugs and vaccination are unclear due to the short duration of clinical testing, eg, chloroquine and remdesivir. ${ }^{22,23}$ Moreover, Johnson \& Johnson's Janssen COVID-19 vaccine may be possibly associated with thrombosis and Cytopenia syndrome (See: https://www.cdc.gov/coronavirus/ 2019-ncov/vaccines/safety/adverse-events.html). Besides, some side effects may not appear, bringing about controversy whether medicine or vaccine has been applied. Controversy also promotes infodemic. Rumors and conspiracy theories about COVID-19 spread fast, ${ }^{86}$ hindering the promotion of vaccination in various countries (See: https://www.nature. com/articles/d41586-021-00997-x).

\section{Study Limitation}

However, this study has some limitations. (1) The lack of authoritative SARS research topic classification. This study does not indicate that the reference to other research topic classification and other text analysis methods may lead to different results. (2) Some co-occurrence items may be divided into different research topics based on the content of the article in which they are judged. (3) The parallel model provides a dimensional explanation for the rapid response of the COVID-19 scientific research and the speed of epidemic prevention and control that is not proportional to the time, ignoring other factors. (4) Furthermore, mental health has not been covered in the main topics of John Hopkins's classification on COVID-19 research. The effects of the pandemic on mental health or recovery of professionals, patients, and residents in lockdown areas have attracted widespread attention since the beginning of the pandemic. ${ }^{87,88}$

\section{Conclusion}

This study indicated that the speed of scientific research response to different topics in COVID-19 occurs in parallel, consistent with the parallel innovation model. Although the high uncertainty aspect in COVID-19 and limitation of rapid research output may affect the time-consuming advantage of the parallel model, the crucial role of scientific research cannot be ignored. Although COVID-19 research has provided information for updating and modifying the prevention measures and the rapid development of vaccine drugs, adhering to public health strategies, including vaccination, is crucial. Notably, the rapid prevention and control of the pandemic cannot fully rely on scientific research in an uncertain environment. Although scientists have made a considerable effort to assist or guide COVID-19 pandemic prevention and control, the absence of close cooperation of multi-party, such as the government selection of prevention strategies and the public's obedience to the management measures, has led to the continuous spread of the pandemic. Therefore, the public should exclusively expand their concerns from scientific research to other behaviors. 


\section{Acknowledgments}

We would like to thank Dr. Maotian Zhou for his assistance in this research.

\section{Funding}

This research was supported by the The National Social Science Fund of China (grant 21CSH074).

\section{Disclosure}

The authors declare that they have no conflicts of interest in this work.

\section{References}

1. Martín-Acebes MA, Saiz JC. The scientific response to zika virus. J Clin Med. 2019;8(3):369. doi:10.3390/jcm8030369

2. Lurie N, Manolio T, Patterson AP. et al. Research as a part of public health emergency response. Mass Med Soc. 2013;368(13):1251-1255.

3. Hyde R. von der Leyen admits to COVID-19 vaccine failures. Lancet. 2021;397(10275):655-656. doi:10.1016/S0140-6736(21)00428-1

4. Udugama B, Kadhiresan P, Kozlowski HN, et al. Diagnosing COVID-19: the disease and tools for detection. ACS nano. 2020;14(4):3822-3835. doi:10.1021/acsnano.0c02624

5. Lurie N, Saville M, Hatchett R, et al. Developing Covid-19 vaccines at pandemic speed. N Engl J Med. 2020;382(21):1969-1973. doi:10.1056/ NEJMp2005630

6. Kambhampati SB, Vaishya R, Vaish A. Unprecedented surge in publications related to COVID-19 in the first three months of pandemic: a bibliometric analytic report. J Clin Orthop Trauma. 2020;11(Suppl 3):S304. doi:10.1016/j.jcot.2020.04.030

7. Bagdasarian N, Cross G, Fisher D. Rapid publications risk the integrity of science in the era of COVID-19. BMC Med. 2020;18(1):1-5. doi:10.1186/s12916-020-01650-6

8. Kwon D. How swamped preprint servers are blocking bad coronavirus research. Nature. 2020;581(7807):130-131. doi:10.1038/d41586-02001394-6

9. Phaal R, O’Sullivan E, Routley M, et al. A framework for mapping industrial emergence. Technol Forecast Soc Change. 2011;78(2):217-230. doi:10.1016/j.techfore.2010.06.018

10. Kessler EH, Chakrabarti AK. Concurrent development and product innovations. In: The Dynamics of Innovation. Springer; 1999:277-299.

11. Millson MR, Raj S, Wilemon D. A survey of major approaches for accelerating new product development. J Product Innov Manag. 1992;9(1):53-69.

12. Salerno MS, Silva DOD, Bagno RB, et al. Innovation processes: which process for which project? Technovation. 2015;35:59-70. doi:10.1016/j. technovation.2014.07.012

13. Sørensen F, Mattsson J. Speeding up innovation: building network structures for parallel innovation. Int J Innov Manag. 2016;20(2):1650024. doi:10.1142/S1363919616500249

14. Tidd J, Bessant JR. Managing Innovation: Integrating Technological, Market and Organizational Change. John Wiley \& Sons; 2020.

15. Phillips S, Williams MA. Confronting our next national health disaster-long-haul Covid. $N$ Engl J Med. 2021;385(7):577-579. doi:10.1056/ NEJMp2109285

16. Loch CH, Terwiesch C. Communication and uncertainty in concurrent engineering. Manag Sci. 1998;44(8):1032-1048. doi:10.1287/ mnsc.44.8.1032

17. Bhuiyan N, Gerwin D, Thomson V. Simulation of the new product development process for performance improvement. Manag Sci. 2004;50 (12):1690-1703. doi:10.1287/mnsc. 1040.0309

18. Valle S, Vázquez-Bustelo D. Concurrent engineering performance: incremental versus radical innovation. Int J Prod Econ. 2009;119(1):136-148 doi:10.1016/j.ijpe.2009.02.002

19. Handfield RB. Effects of concurrent engineering on make-to-order products. IEEE Trans Eng Manage. 1994;41(4):384-393. doi:10.1109/ 17.364562

20. Cortegiani A, Catalisano G, Ippolito M, et al. Retracted papers on SARS-CoV-2 and COVID-19. Br J Anaesth. 2021;126(4):e155-e156. doi:10.1016/j.bja.2021.01.008

21. Brierley L. Lessons from the influx of preprints during the early COVID-19 pandemic. Lancet Planet Health. 2021;5(3):e115-e117. doi:10.1016/ S2542-5196(21)00011-5

22. Singh H, Chauhan P, Kakkar AK. Hydroxychloroquine for the treatment and prophylaxis of COVID-19: the journey so far and the road ahead. Eur J Pharmacol. 2021;890:173717. doi:10.1016/j.ejphar.2020.173717

23. Wang Y, Zhang D, Du G, et al. Remdesivir in adults with severe COVID-19: a randomised, double-blind, placebo-controlled, multicentre trial. Lancet. 2020;395(10236):1569-1578. doi:10.1016/S0140-6736(20)31022-9

24. McDermott C, Handfield R. Concurrent development and strategic outsourcing: do the rules change in breakthrough innovation? J High Technol Manag Res. 2000;11(1):35-57. doi:10.1016/S1047-8310(00)00020-1

25. Cheng X, Tang S. Research on parallel model in the stage of scientific research of graphene in China. Stud Sci Sci. 2019;37(6):9.

26. Zhu N, Zhang D, Wang W, et al. A novel coronavirus from patients with pneumonia in China, 2019. N Engl J Med. 2020;382(8):727-733. doi:10.1056/NEJMoa2001017

27. Schmoch U. Double-boom cycles and the comeback of science-push and market-pull. Res Policy. 2007;36(7):1000-1015. doi:10.1016/j. respol.2006.11.008

28. Rothwell R. Successful industrial innovation: critical factors for the 1990s. R\&D Manag. 1992;22(3):221-240. doi:10.1111/j.1467-9310.1992. tb00812. $\mathrm{x}$

29. Galanakis K. Innovation process. Make sense using systems thinking. Technovation. 2006;26(11):1222-1232. doi:10.1016/j. technovation.2005.07.002 
30. Kline SJ, Rosenberg N. An overview of innovation. The positive sum strategy: harnessing technology for economic growth. Natl Acad Sci USA. 1986;35:36.

31. Meissner D, Kotsemir M. Conceptualizing the innovation process towards the 'active innovation paradigm'-trends and outlook. $J$ Innov Entrepreneurship. 2016;5(1):1-18. doi:10.1186/s13731-016-0042-z

32. Barbieri JC, Álvares ACT. Sixth generation innovation model: description of a success model. Rev Adm Inov. 2016;13(2):116-127. doi:10.1016/j. rai.2016.04.004

33. Buijs J. Modelling product innovation processes, from linear logic to circular chaos. Creativity Innov Manag. 2003;12(2):76-93. doi:10.1111/14678691.00271

34. Sobek II, Ward AC, Liker JK. Toyota's principles of set-based concurrent engineering. MIT Sloan Manag Rev. 1999;40(2):67.

35. Koufteros X, Vonderembse M, Doll W. Concurrent engineering and its consequences. J Oper Manag. 2001;19(1):97-115. doi:10.1016/S0272-6963 (00)00048-6

36. Deshpande A. Concurrent engineering, knowledge management, and product innovation. J Oper Strat Plan. 2018;1(2):204-231. doi:10.1177/ 2516600X18816204

37. Rihar L, Kušar J. Implementing concurrent engineering and QFD method to achieve realization of sustainable project. Sustainability. 2021;13 (3):1091. doi:10.3390/su13031091

38. Wheelwright SC, Clark KB. Revolutionizing Product Development: Quantum Leaps in Speed, Efficiency, and Quality. Simon and Schuster; 1992.

39. Susman GI, Dean JW. Strategic use of computer-integrated manufacturing in the emerging competitive environment. Comput Integr Manuf Syst. 1989;2(3):133-138. doi:10.1016/0951-5240(89)90003-7

40. Blackburn JD, Hoedemaker G, Van Wassenhove LN. Concurrent software engineering: prospects and pitfalls. IEEE Trans Eng Manage. 1996;43 (2):179-188. doi:10.1109/17.509983

41. Calantone RJ, Di Benedetto CA. Performance and time to market: accelerating cycle time with overlapping stages. IEEE Trans Eng Manag. 2000;47(2):232-244. doi:10.1109/17.846790

42. Kusiak A, Park K. Concurrent engineering: decomposition and scheduling of design activities. Int J Prod Res. 1990;28(10):1883-1900. doi:10.1080/00207549008942841

43. Shenas DG, Derakhshan S. Organizational approaches to the implementation of simultaneous engineering. Int J Oper Prod Manag. 1994;14 (10):30-43. doi:10.1108/01443579410067234

44. Herder PM, Weijnen MP. A concurrent engineering approach to chemical process design. Int J Prod Econ. 2000;64(1-3):311-318. doi:10.1016/ S0925-5273(99)00068-7

45. Uttal B. Speeding new ideas to market. Fortune. 1987;115(5):62.

46. AitSahlia F, Johnson E, Will P. Is concurrent engineering always a sensible proposition? IEEE Trans Eng Manag. 1995;42(2):166-170. doi: $10.1109 / 17.387269$

47. Yassine AA, Chelst KR, Falkenburg DR. A decision analytic framework for evaluating concurrent engineering. IEEE Trans Eng Manag. 1999;46 (2):144-157. doi:10.1109/17.759142

48. Wu Z, McGoogan JM. Characteristics of and important lessons from the coronavirus disease 2019 (COVID-19) outbreak in China: summary of a report of 72314 cases from the Chinese Center for disease control and prevention. JAMA. 2020;323(13):1239-1242. doi:10.1001/jama.2020.2648

49. Rip A, Courtial J. Co-word maps of biotechnology: an example of cognitive scientometrics. Scientometrics. 1984;6(6):381-400. doi:10.1007/ BF02025827

50. Chen X, Chen J, Wu D, et al. Mapping the research trends by co-word analysis based on keywords from funded project. Procedia Comput Sci. 2016;91:547-555. doi:10.1016/j.procs.2016.07.140

51. Letko M, Marzi A, Munster V. Functional assessment of cell entry and receptor usage for SARS-CoV-2 and other lineage B betacoronaviruses. Nat Microbiol. 2020;5(4):562-569. doi:10.1038/s41564-020-0688-y

52. Salomone TA. What Every Engineer Should Know About Concurrent Engineering. Routledge; 2019.

53. Karningsih PD, Anggrahini D, Syafi'i MI. Concurrent engineering implementation assessment: a case study in an Indonesian manufacturing company. Procedia Manuf. 2015;4:200-207. doi:10.1016/j.promfg.2015.11.032

54. Duan D, Xia Q. Evolution of scientific collaboration on COVID-19: a bibliometric analysis. Learn Publ. 2021;34(3):429-441. doi:10.1002/ leap. 1382

55. Porter SJ, Hook DW. How COVID-19 is Changing Research Culture. London: Digital Science; 2020.

56. Vlasschaert C, Topf J, Hiremath S. Proliferation of papers and preprints during the COVID-19 pandemic: progress or problems with peer review? Adv Chronic Kidney Dis. 2020;27(5):418-426. doi:10.1053/j.ackd.2020.08.003

57. Berg JM, Bhalla N, Bourne PE, et al. Scientific community. Preprints for the life sciences. Science. 2016;352(6288):899-901. doi:10.1126/science. aaf9133

58. Kobarg S, Stumpf-Wollersheim J, Welpe IM. More is not always better: effects of collaboration breadth and depth on radical and incremental innovation performance at the project level. Res Policy. 2019;48(1):1-10. doi:10.1016/j.respol.2018.07.014

59. Chandy RK, Tellis GJ. The incumbent's curse? Incumbency, size, and radical product innovation. J Mark. 2000;64(3):1-17. doi:10.1509/ jmkg.64.3.1.18033

60. Zhong N, Zeng G. What we have learnt from SARS epidemics in China. BMJ. 2006;333(7564):389-391. doi:10.1136/bmj.333.7564.389

61. Chen D, Zhao XQ, Miao YG. et al. Analysis of the global coronavirus related research status and its enlightenment for the present and future. Chin J Clin Med. 2020;27(1):1-12.

62. Nagy A, Alhatlani B. An overview of current COVID-19 vaccine platforms. Comp Struct Biotechnol J. 2021;19:2508-2517. doi:10.1016/j. csbj.2021.04.061

63. Xu Z, Wang P. Potential anti 2019-nCoV drug: remdesivir. Chin J Mod Appl Pharm. 2020;37(3):264-268.

64. Barton CM, Alberti M, Ames D, et al. Call for transparency of COVID-19 models. Science. 2020;368(6490):482-483. doi:10.1126/science. abb8637

65. Alvarez MM, González-González E, Trujillo-de Santiago G. Modeling COVID-19 epidemics in an excel spreadsheet to enable first-hand accurate predictions of the pandemic evolution in urban areas. Sci Rep. 2021;11(1):1-12. doi:10.1038/s41598-021-83697-w 
66. Wynants L, Van Calster B, Collins GS, et al. Prediction models for diagnosis and prognosis of covid-19: systematic review and critical appraisal. BMJ. 2020;369:m1328. doi:10.1136/bmj.m1328

67. Kucharski AJ, Russell TW, Diamond C, et al. Early dynamics of transmission and control of COVID-19: a mathematical modelling study. Lancet Infect Dis. 2020;20(5):553-558. doi:10.1016/S1473-3099(20)30144-4

68. van Riel D, de Wit E. Next-generation vaccine platforms for COVID-19. Nat Mater. 2020;19(8):810-812. doi:10.1038/s41563-020-0746-0

69. Zhou P, Yang X-L, Wang X-G, et al. A pneumonia outbreak associated with a new coronavirus of probable bat origin. Nature. 2020;579 (7798):270-273. doi:10.1038/s41586-020-2012-7

70. Lu J, Zhang Y, Cheng G, et al. [Clinical characteristics and outcomes of adult critically ill patients with COVID-19 in Honghu, Hubei Province]. Nan Fang Yi Ke Da Xue Xue Bao. 2020;40(6):778-785. Chinese. doi:10.12122/j.issn.1673-4254.2020.06.02

71. Petrosillo N, Viceconte G, Ergonul O, et al. COVID-19, SARS and MERS: are they closely related? Clin Microbiol Inf. 2020;26(6):729-734. doi:10.1016/j.cmi.2020.03.026

72. Li W, Shi Z, Yu M, et al. Bats are natural reservoirs of SARS-like coronaviruses. Science. 2005;310(5748):676-679. doi:10.1126/science.1118391

73. Sah P, Fitzpatrick MC, Zimmer CF. et al. Asymptomatic SARS-CoV-2 infection: a systematic review and meta-analysis. Proc Natl Acad Sci USA. $2021 ; 118: 34$

74. Mahase E. Covid-19: where are we on vaccines and variants? BMJ. 2021;372:N597. doi:10.1136/bmj.n597

75. Lauer SA, Grantz KH, Bi Q, et al. The incubation period of coronavirus disease 2019 (COVID-19) from publicly reported confirmed cases: estimation and application. Ann Intern Med. 2020;172(9):577-582. doi:10.7326/M20-0504

76. Belay AM, Torp O, Thodesen C. Managing concurrent construction projects using knowledge management and set-based thinking. Procedia Eng. 2016;164:235-242. doi:10.1016/j.proeng.2016.11.615

77. Hoedemaker GM, Blackburn JD, Van Wassenhove LN. Limits to concurrency. Decis Sci. 1999;30(1):1-18. doi:10.1111/j.1540-5915.1999.tb01599.x

78. Palayew A, Norgaard O, Safreed-Harmon K, et al. Pandemic publishing poses a new COVID-19 challenge. Nat Hum Behav. $2020 ; 4(7): 666-669$. doi:10.1038/s41562-020-0911-0

79. Glasziou PP, Sanders S, Hoffmann T. Waste in covid-19 research. BMJ. 2020;369:m1847. doi:10.1136/bmj.m1847

80. Zarocostas J. How to fight an infodemic. Lancet Planet Health. 2020;395(10225):676.

81. DiMasi JA, Feldman L, Seckler A, et al. Trends in risks associated with new drug development: success rates for investigational drugs. Clin Pharmacol Ther. 2010;87(3):272-277. doi:10.1038/clpt.2009.295

82. Li Z, Guo Z, Xu F. Clinical medication response under new major infectious disease: off-label use and compassionate use. J Pharm Pract. 2020;38 (3):207-210.

83. Grein J, Ohmagari N, Shin D, et al. Compassionate use of remdesivir for patients with severe Covid-19. N Engl J Med. 2020;382(24):2327-2336. doi:10.1056/NEJMoa2007016

84. Moore JP, Offit PA. SARS-CoV-2 vaccines and the growing threat of viral variants. JAMA. 2021;325(9):821-822. doi:10.1001/jama.2021.1114

85. Cao M, Su X, Jiang S. Broad-spectrum anti-coronavirus vaccines and therapeutics to combat the current COVID-19 pandemic and future coronavirus disease outbreaks. Stem Cell Rep. 2021;16(3):398-411. doi:10.1016/j.stemcr.2020.12.010

86. Islam MS, Kamal A-HM, Kabir A, et al. COVID-19 vaccine rumors and conspiracy theories: the need for cognitive inoculation against misinformation to improve vaccine adherence. PLoS One. 2021;16(5):e0251605. doi:10.1371/journal.pone.0251605

87. Wang C, Pan R, Wan X, et al. Immediate psychological responses and associated factors during the initial stage of the 2019 coronavirus disease (COVID-19) epidemic among the general population in China. Int J Environ Res Public Health. 2020;17:5.

88. Xiong J, Lipsitz O, Nasri F, et al. Impact of COVID-19 pandemic on mental health in the general population: a systematic review. J Affect Disord. 2020;277:55-64. doi:10.1016/j.jad.2020.08.001

Risk Management and Healthcare Policy

Dovepress

\section{Publish your work in this journal}

Risk Management and Healthcare Policy is an international, peer-reviewed, open access journal focusing on all aspects of public health, policy, and preventative measures to promote good health and improve morbidity and mortality in the population. The journal welcomes submitted papers covering original research, basic science, clinical \& epidemiological studies, reviews and evaluations, guidelines, expert opinion and commentary, case reports and extended reports. The manuscript management system is completely online and includes a very quick and fair peer-review system, which is all easy to use. Visit http://www.dovepress.com/testimonials.php to read real quotes from published authors.

Submit your manuscript here: https://www.dovepress.com/risk-management-and-healthcare-policy-journal 